\title{
Air Bubble Frequency Distribution in the Cavity Zone
}

\author{
Bai Ruidi ${ }^{1}$, Liu Shanjun ${ }^{2}$ and Wang $\mathrm{Wei}^{3}$ \\ State Key Laboratory of Hydraulics and Mountain River Engineering, Sichuan University, Chengdu 610065, China
}

Received: December 14, 2016 / Accepted: December 20, 2016 / Published: April 30, 2017.

\begin{abstract}
In this paper, a series of experiments were carried out on the air concentration distribution. In the cavity zone, the air bubble frequency distribution was similar to the air concentration distribution. The air bubble frequency increased from the bottom and then decreased near the unaerated black water region. The position of the maximum air bubble frequency $f_{\max }$ moved downwards. At the air-water cross section, the relationship between the air bubble frequency and the air concentration was self-similar, the position of the maximum air bubble frequency caused by the air-water discontinuity gradually approached $C=0.50$ with the development of aeration. Meanwhile, the dimensionless air bubble frequency in the cavity zone followed a parabolic function.
\end{abstract}

Key words: Chute, air bubble, air concentration, frequency.

\section{Introduction}

As a clean and safe energy, hydroelectric power, together with thermal power and nuclear power, constitutes three central pillars of the power in today's world. The cavitation damage often takes place in spillways tunnels with high-speed flows, so it is necessary to avoid the potential risk of cavitation erosion. The air concentration near the bottom of $1-2 \%$ reduce substantially the cavitation erosion and above $5-7 \%$ no erosion was observed. Therefore, spillways and flood-discharging tunnels are usually equipped with chute aerator, which is quite widespread as it has been proved to be a successful countermeasure in the Grand Goulee Dam since 1960 [1]. Chute aerators separate the flow from the chute bottom, and air can enter into the flow through the lower surface in the cavity zone due to high turbulence eddies close to the air-water interface $[2,3]$.

Chanson [4-6] focused on the air concentration distribution and the velocity distribution in the cavity and divided the air entrainment process into four parts: jet entrainment, air entrainment through the upper and

Corresponding author: Wei Wang, Ph.D., professor, research fields: hydraulics and river dynamics. lower free surfaces of the jet, plunging jet entrainment at the intersection and the rollers, and air recirculation in the cavity below the jet. Chanson [4] and Kramer et al. [7] found that a strong de-aeration process occurred downstream of the impact point and indicated that the strong de-aeration could be observed at the free surface. Pfister and Hager [8] also found the bottom air concentration decreased near the jet reattachment. The studies of Pfister and Hager [8-10] described the air concentration characteristics in both the near and the far aerator fields based on an extensive test program and divided the air transport downstream of chute aerators into three zones: jet zone, reattachment and the spray zone, and far-field zone.In this paper, we focused on the air bubble frequency distribution in the cavity zone.

\section{Hydraulics Model}

The experiments were conducted in a rectangular chute that was $0.25 \mathrm{~m}$ wide and $5 \mathrm{~m}$ long, which was fabricated from PMMA. The roughness height of the chute was $0.01 \mathrm{~mm}$. Water discharge up to $500 \mathrm{~L} / \mathrm{s}$ was supplied by a constant head system and measured to an accuracy of $\pm 1 \%$ with a rectangular sharp-crested weir. The cavity was kept sufficiently open to the atmosphere so that the pressure in the 
cavity was approximately equal to atmospheric pressure. The flow to the chute was fed through a smooth convergent nozzle. The nozzle had a flat bottom that was aligned with the flume bottom, two elliptic convergent sidewalls and an elliptic convergent roof. The nozzle exit was $0.15 \mathrm{~m}$ high and $0.25 \mathrm{~m}$ wide. The central streamwise air-water velocity and air concentration distribution were measured with a phase-detection needle probe (CQY-Z8a Measurement Instrument, China [11]).

The air-water flow surface was defined along the isoconcentration lines of $C=0.90$ [12, 13]. Pfister and Hager [9] discussed the scale effect relating to the hydraulic model tests and indicated that the scale effect was small if the flow Weber number $W e=$ $V_{0} /\left(\sigma / \rho_{w} h_{0}\right)^{0.5}>140$ and the Reynolds number $R e=$
$V_{0} h_{0} / v>2 \times 10^{5}$. All the experiment tests ranged within $180 \leq W e \leq 405$ and $5 \times 10^{5} \leq R e \leq 12 \times 10^{5}$. Hence the scale effect was argued to small.

\section{Experiment Results}

The flow to the chute was fed through a pressure inlet and the approach flow was unaerated. As the upper and lower aeration thickness increased in the streamwise direction, the thickness of the core of unaerated black water between the lower and the upper aeration regions gradually decreased. In all of the experiments, the core of unaerated black water extended along the chute for a distance downstream of a specific location, as shown in Fig. 2, so the effects of the upper jet could be neglected for an independent study of the lower jet.

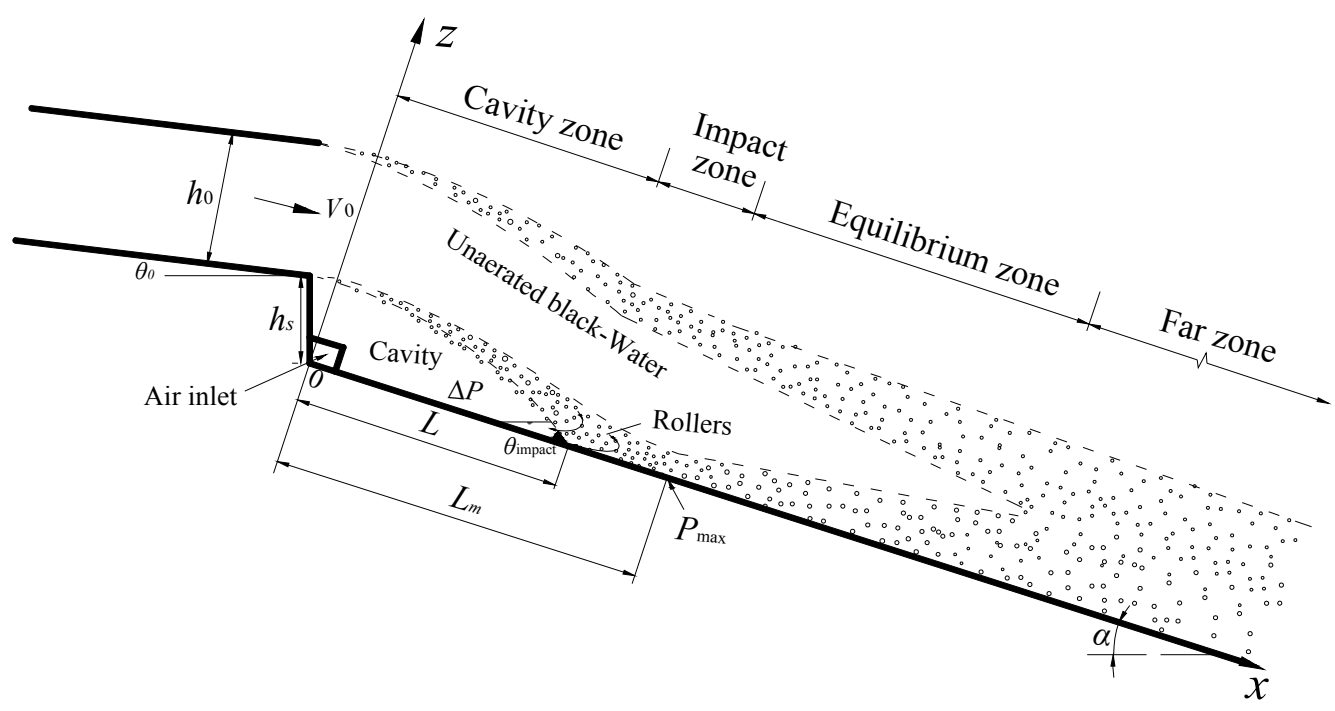

Fig. 1 Definition sketch with relevant parameters.

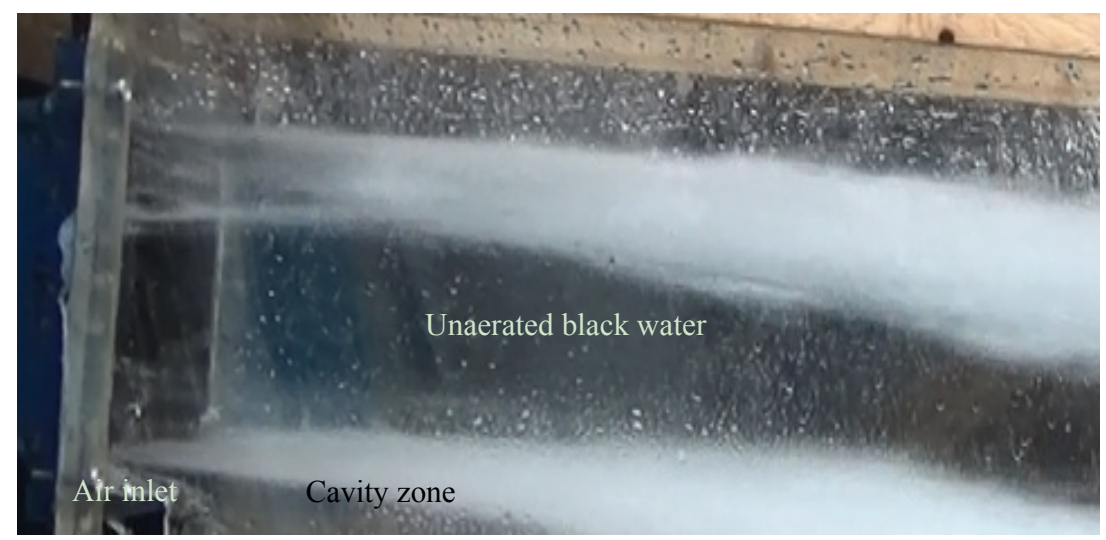

Fig. 2 Photo graph of model test. 


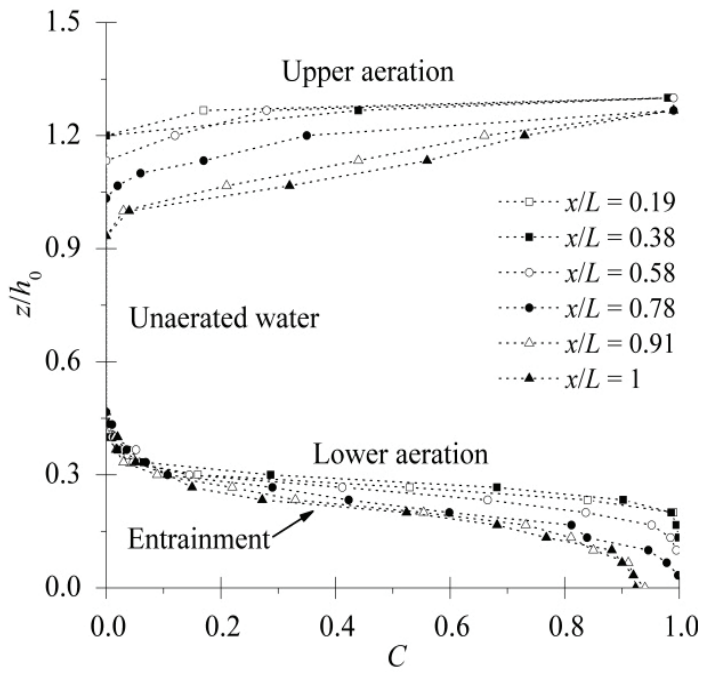

Fig. 3 Air concentration distribution in the cavity zone.

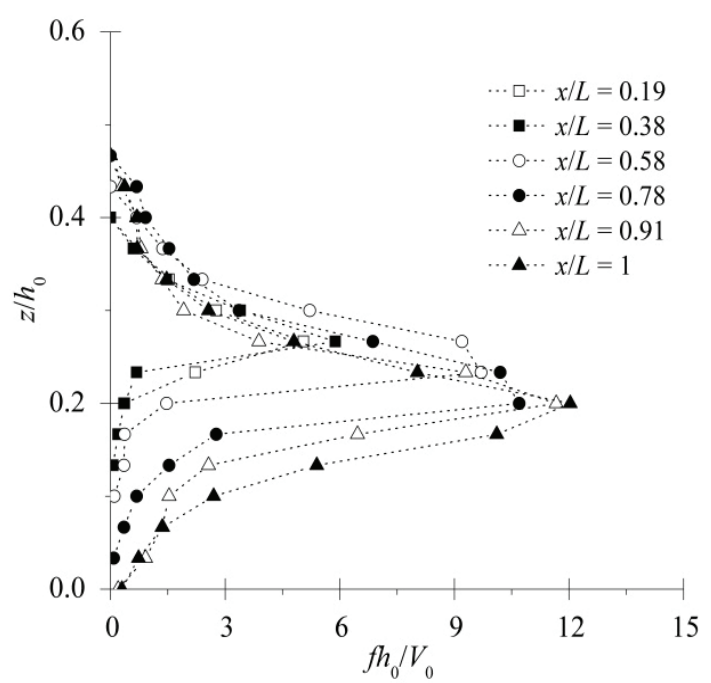

Fig. 4 Air bubble frequency distribution in the cavity zone.

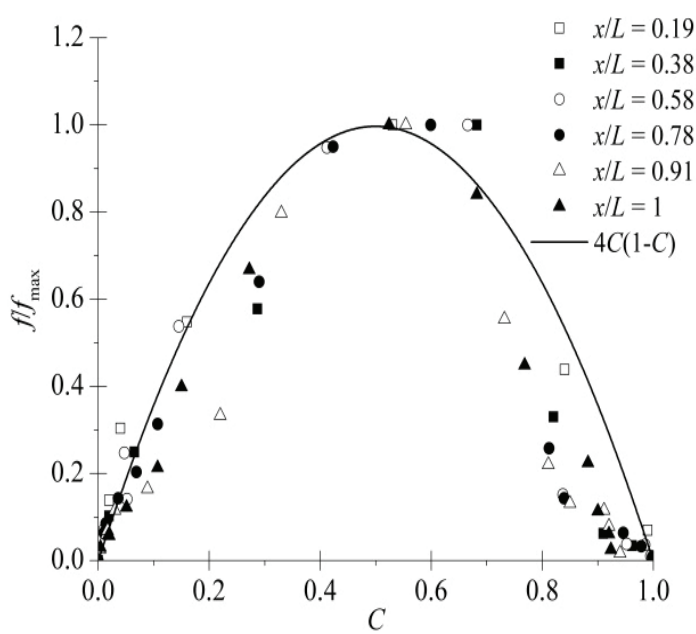

Fig. 5 Relationship between air bubble frequency and air concentration.
The air-water flow structure downstream of the chute aerator is shown in Fig. 2. In the cavity zone, air was entrained into the flow along the lower jet trajectory from the air inlet behind the aerator. The profile of $x / L=0.19$ indicated that little air was entrained into the flow through the lower surface and the section consisted almost entirely of unaerated black water. Even where the lower jet impacted the chute bottom at $x / L=1$, unaerated black water predominated, as shown in Fig. 3.

In the cavity zone, the air bubble frequency distribution was similar to the air concentration distribution, as shown in Fig. 4. The air bubble frequency increased from the bottom and then decreased near the unaerated black water region. The position of the maximum air bubble frequency $f_{\max }$ moved downwards. In the cavity zone, the position of the maximum air bubble frequency was generally in the region of high air concentration, where bubbles were the main type of air-water structure because of the water drops.

\section{Conclusions}

Self-similarity, closely linked with dynamic similarity, is a powerful tool in turbulence flow research and high-velocity air-water flows. At the air-water cross section, the relationship between the air bubble frequency and the air concentration was self-similar; the position of the maximum air bubble frequency caused by the air-water discontinuity gradually approached $C=0.50$ with the development of aeration. Meanwhile, the dimensionless air bubble frequency in the cavity zone followed a parabolic function of $f / f_{\max }=4 C(1-C)$, as shown in Fig. 5.

\section{Acknowledgements}

This work was supported by the National Key Research and Development Program (Grant No. 2016YFC0401707), and the National Natural Science Foundation of China (Grant No. 51479129 and Grant No. 51679157). 


\section{References}

[1] Glazov, A. I. 1984. "Calculation of the Air-Capturing Ability of a Flow Behind an Aerator Ledge." Hydrotechnical Construction 18 (11): 554-8.

[2] Rutschmann, P., and Hager, W. H. 1990. "Air Entrainment by Spillway Aerators." Journal of Hydraulic Engineering 116 (6): 765-82.

[3] Wood, I. R. 1991. "Free Surface Air Entrainment on Spillways." IAHR Hydraulic Structures Design Manual 4, Wood, I. R. (ed.), A. A. Balkema, Rotterdam, Netherlands: 55-84.

[4] Chanson, H. 1990. "Study of Air Demand on Spillway Aerator." Journal of Fluids Engineering 112 (3): 343-50.

[5] Chanson, H. 1996. "Air Bubble Entrainment in Turbulent Water Jets Discharging into the Atmosphere." Australian Civil Engineering Transactions 39 (1): 39-48.

[6] Chanson, H. 1997. "Measuring Air-Water Interface Area in Supercritical Open Channel Flow." Water Research 31 (6): 1414-20.
[7] Kramer, K., Hager, W. H., and Minor, H.-E. 2006. "Development of Air Concentration on Chute Spillways." Journal of Hydraulic Engineering 132 (9): 908-15.

[8] Pfister, M., and Hager, W. H. 2010. "Chute Aerators I: Air Transport Characteristics." Journal of Hydraulic Engineering 136 (6): 352-9.

[9] Pfister, M., and Hager, W. H. 2010. "Chute Aerators II: Hydraulic Design." Journal of Hydraulic Engineering 136 (6): 360-7.

[10] Pfister, M., and Hager, W. H. 2011. "Chute Aerators: Pre Aerated Approach Flow." Journal of Hydraulic Engineering 137 (11): 1452-61.

[11] Chen, X. P., and Shao, D. C. 2006. "Measuring Bubbles Sizes in Self-aerated Flow." Water Resources Hydropower Engineering 37 (10): 33-6. (In Chinese).

[12] Felder, S., and Chanson, H. 2014. "Triple Decomposition Technique in Air-Water Flows: Application to Instationary Flows on a Stepped Spillway." International Journal of Multiphase Flow 58: 139-53.

[13] Hager, W. H. 1991. "Uniform Aerated Chute Flow." Journal of Hydraulic Engineering 117 (4): 528-33. 